\title{
Sustainable Development of Corporate Reputation - Reputation analysis of the selected brands owned by the family businesses
}

\author{
Frantisek Pollak ${ }^{1, *}$, Peter Markovic ${ }^{2}$, Jarmila Strakova ${ }^{1}$, and Petra Partlova ${ }^{1}$ \\ ${ }^{1}$ Institute of Technology and Business in Ceske Budejovice, Faculty of Corporate Strategy, \\ Department of Management, Nemanicka 436/7, 37010 Ceske Budejovice, Czech Republic \\ ${ }^{2}$ University of Economics in Bratislava, Faculty of Business Management, Department of Business \\ Finance, Dolnozemska cesta 1/b, 85235 Bratislava, Slovakia
}

\begin{abstract}
Research background: The paper discusses the issue of sustainable development of corporate reputation, more specifically discusses the issue of traditional and innovative approaches to reputation management of selected global brands owned by the family businesses.

Purpose of the article: The main aim of the paper itself is to present the available ways and methods of measuring the phenomenon of reputation, especially online reputation, as the modern challenge for responsible and sustainable development of the perceived image of subjects, as their very fragile intangible assets.

Methods: Selected European and US brands owned by the family businesses were analyzed by the standardized multifactor reputation analysis TOR in the virtual environment of the Internet. Taking into account all relevant factors, the online ratings were normalized and then compared against the offline ratings. Relationships between factors were examined to identify and describe basic facts affecting the online reputation of subjects in the hyper-competitive market environment, especially for the European and for the US market.

Findings \& Value added: The results of analysis providing a comprehensive view on the issue of the selected approached to the sustainable development of corporate reputation. Although literature offers a wide range of approaches to measure reputation, the presented methodology offers a relatively simple and fairly accurate form for active reputation management, thus providing an effective tool for increasing the competitiveness for subjects trying to maximize their market advantages against their competitors.
\end{abstract}

Keywords: reputation; brand; business succession; family business

JEL Classification: $O 34 ; M 14 ; M 2$

\footnotetext{
* Corresponding author: frank.pollak@acuityeng.com
} 


\section{Introduction}

The issue of a family business is diverse; we know from practice that small and medium-sized enterprises are the backbone of the economies of market economy countries. A significant part of these enterprises was established just as a family business. Business practice gives us examples where even large corporations were either established or even persisted as a family business to these days. Assuming that a family holds at least $32 \%$ of the voting shares in a publicly traded company, or the family has at least a $50 \%$ stake in a private company, the company can be declared a family business [1]. As this study is a frequent part of extensive research in the field of family business, we will look at one of the important aspects of competitiveness, namely the aspect of reputation building. As it is difficult to identify specific contexts in research files, we have decided to use the sample of family businesses narrowed to the most successful businesses on both sides of the Atlantic Ocean for our analysis. We selected the 10 most valuable brands of 2019 [2], five for each of the Atlantic shores, owned by the parent company falling under the definition of a family business. On our sample, we carry out a comprehensive reputation analysis, focusing on reputation in the Internet environment and the subsequent findings will be described in a geographical and market context. The results of analysis providing a comprehensive view on the issue of the selected approached to sustainable development of corporate reputation. Although literature offers a wide range of approaches to measure reputation, the presented methodology offers a relatively simple and fairly accurate form for active reputation management, thus providing an effective tool for increasing the competitiveness for subjects trying to maximize their market advantages against their competitors.

\section{Theoretical background for the analysis}

In the next chapter we will discuss the key issues necessary for the analysis itself, namely the issues of image, trust and reputation.

\subsection{Image- semantic, marketing and psychological term}

According many domestic and foreign authors [3-5], the first usually cited work on the image in connection to marketing is the publication by Gardner and Levy, The product and the brand, dated to the year 1955, which addresses, among other things, the fact that the brand and overall image of a given product may be a buying motive number one, more important than actual technological and technical properties of a product or service. It is worth to mention other publications, the image - the work written in English from the year 1956 and the contribution of McCann Erickson created in New York in the year 1959. The breakthrough years for European contributions and publications are 1961, 1962, 1968, and 1971. From the more recent, we may mention the work Strategic Marketing for Non-profit Organizations from the year 1991, and others. The associated understanding of the company's image is usually defined as a result of the interaction of all knowledge, opinions, impressions and experience, which the public has in relation to a given firm, company or organization [6]. It can be generally stated, that building of a positive image is not an easy task, but when a company already has it, it is extremely easy to be thwarted by one deed, act or step and thus a company may reverse its corporate image by 180 degrees. And correcting is then very, very difficult. The use of the image problem for the purposes of marketing is not a strictly philosophical, literary or marketing approach, but it is, for example, also an empirical term of social psychology with measurable dimensions. Thus, analysis of mental processes and responses to stimuli, which enable and support the formation of an image, is necessary for the most complex understanding of an image [3]. 
Nevertheless, possibilities of people in today's information explosion, which surrounds them, unfortunately, are not infinite. A human replaces deficiency or an excess of information by a complex of attitudes, assumptions and feelings [7]. It is related to the fact, that if we see the image as a set of ideas, attitudes, opinions or experience towards a certain object, but also as a consumer's perception of an institution, product, brand, shop or human, which, however, may but may not be based on the reality, we are not wrong [6].

\subsection{Trust, reputation and online reputation- concepts, basic features and conditions for development}

Trust has many dimensions, and it is a part of interpersonal as well as business relationships almost at every turn. In 1974, the laurate of Nobel prize for Economics, Keneth Arrow, stated that trust is an irreplaceable accept in every economic exchange and its presence is an assumption of the effectiveness and mutual gainfulness of any transaction [8]. Many authors [9-11], however, agree on claims that it is not easy to express a clear definition of this "elusive" concept. It is necessary to perceive it as a holistic concept. There have been conducted various studies, which were aimed at the description of the concept of trust through the form of stage procedure of trust within a certain relationship. They also agree on the identification of basic features of trust - a reputation, brand, strengthening of trust and on the conditions, the existence of which is necessary for strengthening and building of trust, for which they determined the willingness to take risk and the feeling of interdependence. If there is not a certain degree of risk in relationships, activities would be carried out with an absolute certainty and obviosity and it would not be justified to build any trust. Trust fulfils every successful company in millions of different ways. No institutions could operate without it [12]. Trust is a firm belief that we can rely on a certain person [13]. An alternative definition is offered by Anguera-Torrell [14], according to him, trust is a belief that those who we are dependent on will fulfil our expectations connected to them. These expectations depend on our critical evaluation of responsibility of another human being to satisfy our needs. Tavakolifard [15] claims that the generally accepted definition of trust is still missing, despite extensive studies of philosophers, sociologists and psychologists. A reputation may be, in some cases equated to goodwill. It is not considered as a mistake at all. The term is semantically related to a position or rank acquired in opinions of others, similarly as an image, for which a reputation is a complementary and integrated part [16]. Naturally, similarly to trust, a reputation does not carry only one dimension. Many domestic and foreign authors [17, 18] describe online reputation as the overall presence of a particular subject on the Internet. At present, from a layman's point of view, presence on the Internet is equal to presence on social media, and from a professional point of view, this view is to a large extent limited. Reputation is not only the domain of social platforms, it is created primarily by users sharing their attitudes and following their interactions through a wide range of tools [19] such as search engines, catalogues, forums, blogs, and so on. Due to the instrumental variety of marketing in the Internet environment, it is recommended that the subjects use the largest possible number of these sub-tools as part of their marketing communications. There is pressure on active marketing communication to eliminate potential threats caused by content moderation or the complete passivity of the subject. The contrast of "one" negative mention in the context of dozens of positive messages will greatly reduce the risk of long-term damage to the reputation of the subject. With the growing number of internet users and the related growth of users of social networks, blogs and pages, where content is generated by users themselves, there is the increase of importance of internet monitoring. With the aim to monitor the internet, there can be used many tools, which continuously index new pages on the internet and compare 
them with monitored phrases such as a name of a product, company, competitors or another key word [20].

\section{Methodology}

The main aim of the paper itself is to present the available ways and methods of measuring the phenomenon of reputation, especially online reputation, as the modern challenge for responsible and sustainable development of the perceived image of subjects, as their very fragile intangible assets. The issue of managing online reputation as a new phenomenon in the form of fragile intangible assets is gradually gaining on the importance and it is becoming one of the essential prerequisites for responsible and sustainable reputation management. We approach the presentation of the issue using advanced multifactor analysis of online reputation of the 10 from the 100 most successful global brands of the year 2019 [2], those that are owned by the family businesses [1], 5 for each of the Atlantic shores. Taking into account all the relevant factors, all online ratings are normalized and then compared against the offline rating presented by the brand value expressed in USD. Relationships between factors are then examined in order to identify and describe basic facts affecting online reputation of subjects in the hyper-competitive market environment of the Internet. Especially for the European and for the US brands. Describing key connections and determinants influencing the reputation of these subjects will certainly help better understanding this, from our point of view, extremely important issue. Within the testing, we considered the entire spectrum of perceiving their reputation since we compared the whole specter of relevant virtual factors and connections measured by us against significant and relevant ranking of the mortar world provided by their brand value. Within our research, we used the methodology of multi-factor analysis of online reputation, namely its modified version TOR [21]. The measurement itself takes place in three steps, in first step, it is necessary to analyse the sentiment of the first ten keyword search results by the methodology of Sentiment analysis introduced by Sasko [20]. To maximize the information value of data we proceeded to the partial automation of determining the sentiment of search results to calculate the force of the sentiment, we used the online DanielSoper free Sentiment Analyzer [22]. Scores for individual results in specific search positions were converted to points according to the original methodology. The sum of points is the starting point for subsequent quantification. For one parameter, the subject can get a maximum of 155 points, the same applies to the minimum number of points, which can acquire the same but negative value in this case [20], one such point is then plus, or minus $0.645 \%$ in percentage terms. In the second step, we identify the determinants of online reputation, for our study, we will call them reputators. As a reputator, we can identify any determinant which has the ability to influence the perceived online reputation of a subject, at the same time, it can be quantified, and it is possible to express its value in percentages. Typically, this can be important web pages of a catalogue type providing different ratings, subjects' profiles on social nets or portals that can significantly influence the perception of the reputation of a selected subject. Given the various business fields entities operate in, reputation determinants cannot be clearly defined in advance. In terms of advantage quantification, it is possible to approach individual reputation determinants by calculation of reputators' competitive score - the number of users (fans/customers/followers) the particular entity has relative to the sum of all tested subjects. The result serves as a basis for calculating the percentage of the reputators' competitive score (CS) of the particular entity. In other words, reputator competitive strength of the particular subject can be calculated as the size ratio of its own tribe [23] indicated as the total number of subject followers/fans/subscribers/to the total amount of tribes of all tested subjects. In the third step, we can proceed to the actual calculation of the overall power of online reputation of a 
specific TOR subject which then serves as a starting point for complex comparison of overall power of reputation across all analysed subjects. The standard equation for TOR calculation as well as for calculation of competitive scores was presented in our previous studies $[4,21,24,25]$. In this case, the value of the overall online reputation (TOR) is an arithmetic average of individual indicators (partial score according to individual determinants).

\section{Results and discussion}

All examined subjects are actively involved in their reputation management both traditional and virtual environments. Study itself will predominantly refer to the virtual Internet environment.

\subsection{Overview table of partial score}

Using the advanced sentiment analysis, we calculated partial score presenting the power of online reputation of entities based on the nature of the first 10 Google search results. Google and its search results are, however, only one of the many ways in which potential customers can access relevant information. Considering the previous research in the field, we identified the following other determinants of online reputation- reputators, in particular: Facebook (total number of followers of the official global profile); Twitter (total number of followers of the official global profile); YouTube (total number of subscribers of the official global profile); Instagram (total number of followers of the official global profile). Each of these reputators has its own system which determines the overall score. But basically, all of them operate with a certain tribe of the customers (followers, fans, subscribers). For the purposes of further analysis scores of partial reputators were unified to the parameter which we named competitive strength, hereafter referred to as CS and converted into a percentage. Before we present our own interpretations, we consider necessary to present partial evaluations of the subjects as well as all relevant indicators in one summary table. Table 1 presents both individual ranking of the brick-and-mortar world and a partial score obtained by quantification of individual reputators and last but not least it shows the overall level of online reputation represented by the TOR indicator:

Table 1. Overall (Total) online reputation

\begin{tabular}{|c|c|c|c|c|c|c|c|c|c|c|}
\hline No. & Subject & $\begin{array}{c}\text { ASA } \\
\text { score } \\
(\%)\end{array}$ & $\begin{array}{c}\text { FC } \\
\text { score } \\
(\%)\end{array}$ & $\begin{array}{c}\text { TC } \\
\text { score } \\
(\%)\end{array}$ & $\begin{array}{c}\text { YC } \\
\text { score } \\
(\%)\end{array}$ & $\begin{array}{c}\text { IC } \\
\text { score } \\
(\%)\end{array}$ & $\begin{array}{c}\text { Number } \\
\text { of pages } \\
\text { indexed } \\
\text { by } \\
\text { Google } \\
\text { (in M) }\end{array}$ & $\begin{array}{c}\text { TOR } \\
\text { score } \\
(\%)\end{array}$ & $\begin{array}{c}\text { TSMC } \\
\text { score } \\
(\%)\end{array}$ & $\begin{array}{c}\text { Brand } \\
\text { Value } \\
\text { (in } \\
\text { MM/B } \\
\text { USD) }\end{array}$ \\
\hline 1. & BMW & 33.54 & 10.10 & 4.95 & 11.14 & 10.18 & 2,320 & 13.98 & 9.09 & 41.44 \\
\hline 2. & Nike & $\overline{38.06}$ & 16.69 & 19.32 & 13.79 & 39.73 & 1,780 & 10.30 & 22.38 & 32.38 \\
\hline 3. & $\begin{array}{l}\text { Louis } \\
\text { Vuitton } \\
\end{array}$ & $\begin{array}{c}- \\
16.77 \\
\end{array}$ & 11.69 & 17.98 & 4.30 & 14.69 & 323 & 6.38 & 12.16 & 32.22 \\
\hline 4. & Chanel & 47.09 & 11.11 & 31.77 & 16.76 & 15.40 & 766 & 24.43 & 18.76 & 22.13 \\
\hline 5. & Hermès & 69.02 & 1.61 & 0.18 & 1.17 & 3.93 & 478 & $15, .8$ & 1.72 & 17.92 \\
\hline 6. & $\mathrm{H} \& \mathrm{M}$ & 64.50 & 18.69 & 20.17 & 26.03 & 13.85 & 303 & 28.65 & 19.69 & 16.35 \\
\hline
\end{tabular}




\begin{tabular}{|c|l|c|c|c|c|c|c|c|c|c|}
\hline 7. & Budweiser & 4.52 & 7.38 & 0.46 & 2.19 & 0.18 & 27 & 2.95 & 2.55 & 16.02 \\
\hline 8. & Ford & 14.84 & 7.86 & 2.94 & 22.61 & 1.55 & 3,450 & 9.96 & 8.74 & 14.33 \\
\hline 9. & Dell & 58.70 & 6.26 & 1.75 & 1.78 & 0.32 & 2,420 & 13.76 & 2.52 & 9.09 \\
\hline 10. & $\begin{array}{l}\text { Jack } \\
\text { Daniel's }\end{array}$ & 28.38 & 8.60 & 0.48 & 0.23 & 0.18 & 26 & 7.58 & 2.37 & 6.35 \\
\hline
\end{tabular}

In the first step, the reputation of the first 10 keyword / brand name search results in google were analysed. As mentioned, we used sentiment analysis in its basic unmodified form. Only organic search results were considered. We used proxy anonymizer to ensure the highest possible value of the results. We have chosen the United States as the country of accession. The search result sentiment at a particular position was calculated from the "Title" and "Description" sections of that result via the DanielSoper free Sentiment Analyzer. Negative sentiment was assigned with values from -100 to -30 . The result is in the range of -30 to +30 was set as neutral, and the result in the range of +30 to +100 was marked as positive sentiment. As expected, the first ranks in the search results were occupied by the entities' own pages. These were followed by references to social media and Wikipedia. As mentioned, we left the determination of the nature of the results to the software. Its functioning is a mystery, given the rather surprising values of measured sentiment in specific cases. However, since all subjects had the same conditions, we consider the results to be objective. In terms of overall results, Hermès followed best by $\mathrm{H} \& \mathrm{M}$ with more than $60 \%$ of the total possible reputation level of search results were clear winners. In the second step, we focused on exploring the power of entities in the social media environment. Since the subject profiles did not include direct evaluation methods, we proceeded with a mediated calculation of the strength of that subject in terms of the size of its tribe. The entities had cumulatively more than 200 million users. Surprisingly, the distribution of the tribe was relatively uniform across the sample. Nike and H\&M have the largest sub-tribe. A surprising finding was that Facebook is not the most preferred platform in terms of total tribe size. Anyhow, when it comes to Twitter, it is just $20 \%$ of the size of Facebook in terms of total tribe size. Surprise was Chanel, who has a large lead on this platform by the largest group of followers. The third analysed platform was YouTube, as the platform is the most expensive in terms of content production, it did not surprise the significant difference in total subscribers versus the total Facebook fans of the surveyed subjects. The total number of subscribers to this media for all entities is less than 10 million. Here, the subject H\&M clearly leads ahead with a comfortable lead over Ford. Surprisingly, Instagram was the dominant platform for disseminating content in terms of overall tribe size. However, given the simple form of dissemination of generally unpretentious content, this could be expected. With almost $40 \%$ of overall tribe, Instagram is dominated by Nike. In the third step, we proceeded to calculate the total strength of the online reputation (TOR). In terms of complete results, our winner is H\&M with almost $30 \%$ of the total online reputation strength. In the second place, Chanel is second with almost $25 \%$ of the total online reputation. For the sake of completeness, we have added to the analysis a parameter of the total competitive strength of the entity on social media (TSMC), which takes the form of the arithmetic mean of the partial achievements of that entity on individual platforms. In this case, Nike is the winner with more than $20 \%$ share of more than half a billion of subscribers of analysed subject profiles. 


\subsection{Outcomes of the analysis- visualization and interpretation}

The following Figure 1 point out some significant outcomes of the analysis:

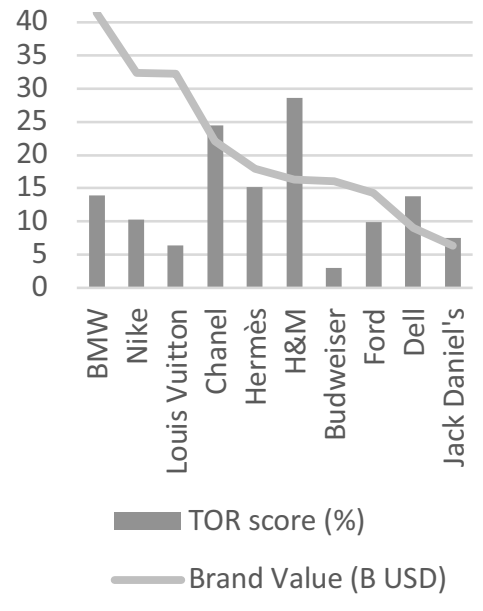

(a)

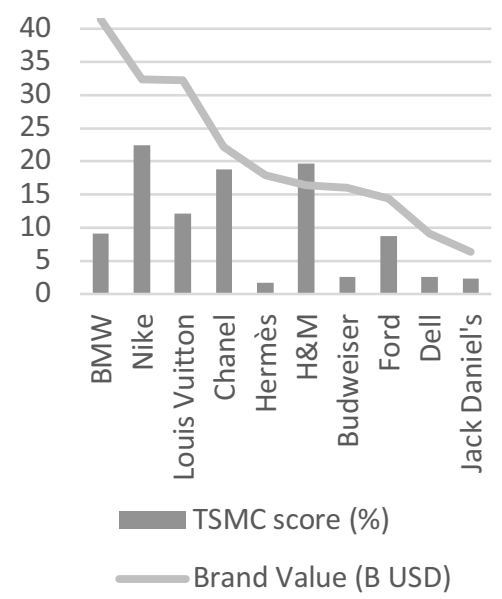

(b)

Fig. 1. (a) Total Online Reputation vs. Brand Value; (b) Online vs. Offline world

From the perspective of interesting findings, we can start by looking at the outlined relationship between the online and offline world. The online world is presented by both the TOR parameter and the TSMC parameter, while the offline world is represented by the market value of the brand. In terms of overall reputation, only four brands, namely Chanel, H\&M, Dell and Jack Daniel's, achieve the outlined value potential. From the point of view of the share of the tribe in social media, only H\&M exceeds its "expected" potential given by the brand value. Given the "expected" potential, looking at the visualized analysis results, it can be stated with a great amount of abstraction that $1 \%$ TOR could be equal to $\$$ 1 billion in terms of brand value (in tables and graphs referred to as B or MM). However, we did not have enough empirical material to investigate this trend more closely.

\subsection{Europe vs. US Brands}

In the following Figure 2 (parts a-d) and Table 2, we can see a comparison of the tags across the Atlantic:

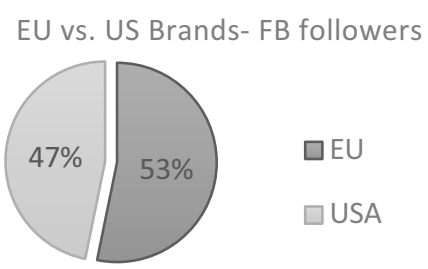

(a)
EU vs. US Brands- YouTube subscribers

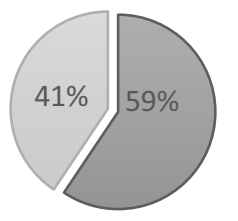

口EU

口USA 


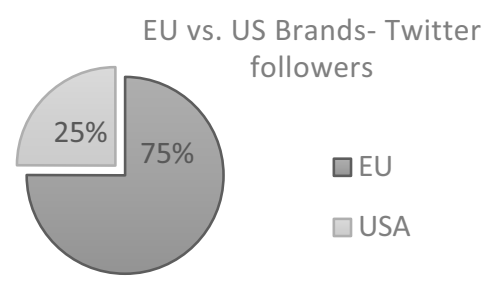

(c)

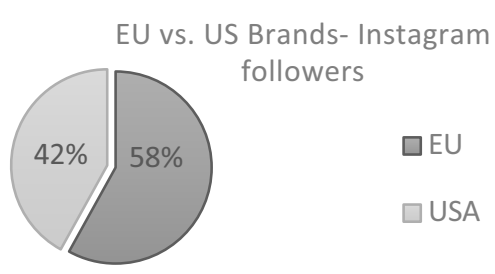

(d)

Fig. 2. Europe vs. US Brands; (a) FB followers; (b) YouTube subscribers; (c) Twitter followers; (d) Instagram followers

A surprising finding is that, from the perspective of the analysed indicators associated with family businesses (and their owned brands), as we can see in Table 2, Europe maintains a significant lead over the United States, namely the value of the analysed brands reaches a total value of 130 billion, while the US lags behind 78 billion.

Table 2. Europe vs. US Brands

\begin{tabular}{|c|c|c|c|c|c|c|}
\hline Brands & $\begin{array}{c}\text { Facebook } \\
\text { Tribe } \\
(\mathbf{n})\end{array}$ & $\begin{array}{c}\text { Twitter } \\
\text { Tribe } \\
(\mathbf{n})\end{array}$ & $\begin{array}{c}\text { YouTube } \\
\text { Tribe } \\
(\mathbf{n})\end{array}$ & $\begin{array}{c}\text { Instagram } \\
\text { Tribe } \\
(\mathbf{n})\end{array}$ & $\begin{array}{c}\text { No. of pages } \\
\text { indexed by } \\
\text { Google }\end{array}$ & $\begin{array}{c}\text { Brand Value } \\
\text { (MM/B } \\
\text { USD) }\end{array}$ \\
\hline $\begin{array}{c}\text { EU } \\
\text { SUM }\end{array}$ & $107,070,672$ & $31,227,427$ & $5,386,000$ & $145,531,320$ & $4,190,000,000$ & 130.060 \\
\hline $\begin{array}{c}\text { USA } \\
\text { SUM }\end{array}$ & $94,159,396$ & $10,381,233$ & $3,681,300$ & $105,170,002$ & $7,703,000,000$ & 78.150 \\
\hline EU & $21,414,134$ & $6,245,485$ & $1,077,200$ & $29,102,664$ & $838,000,000$ & 26.010 \\
AVG & $18,831,879$ & $2,076,247$ & 736,260 & $21,034,000$ & $1,541,000,000$ & 7.710 \\
\hline $\begin{array}{c}\text { USA } \\
\text { AVG }\end{array}$ & \multicolumn{7}{|l}{} & \multicolumn{2}{|c|}{} & & \\
\hline
\end{tabular}

The only parameter in which US brands of the analysed sample overtake the European ones is the number of pages indexed by Google. Table 2 summarized the sums and averages of the cumulative values of the subjects surveyed on both Atlantic shores.

\section{Conclusions}

Based on the findings, we can conclude that sustainable development of reputation management combines offline and online techniques, as both worlds are connected. Even though different environments require specific approaches, recorded different dynamics, and required specific tools. It is almost impossible to be a star only in one world. However, by its nature, online reputation is more fragile. From the analysed entities, it can be stated that family businesses located in Europe show higher activity levels and have higher intangible asset rates in the form of determinants of their online reputation. They also achieve higher market value for their brands. To a certain extent, this is due to the nature of the market as well as the historical tradition. Out of the top 10 European brands, 6 fell into the category "owned by a family business", out of the top 10 American brands, none belonged to this category. Globally, the first brand owned by a family business in the Top 100 rankings is Nike, with a 16th place overall. But from American brands, it is only in its 12th place. It is preceded by brands like Apple, Google, Amazon, Microsoft, etc. The issue, as such, shows more than suitable for a further thorough examination. 
Acknowledgments: This contribution is prepared within the project CE1158 ENTER-transfer.

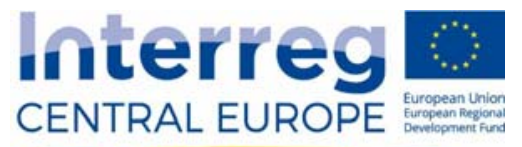

\section{ENTER-transfer}

This contribution is one of the partial outputs of the currently solved research grant VEGA no. $1 / 0240 / 20$

This research was funded by Technology Agency of the Czech Republic, Programme of ETA, project reg. no. TL 0200215- Digital Transformation for Business Model Innovations in Small and Medium Sized Enterprises in the Czech Republic.

\section{References}

1. Bain, D. (2019, June 5). The World's Top 750 Family Businesses Ranking. Retrieved from: https:/www.famcap.com/the-worlds-750-biggest-family-businesses/

2. Interbrand. (2019, December 17). Best Global Brands 2019 Rankings. Retrieved from: https://www.interbrand.com/best-brands/best-global-brands/2019/ranking

3. Vysekalova, J., Mikes, J. (2009). Image a firemni identita. Prague : Grada Publishing.

4. Pollak, F., Dorcak, P., Raceta, N., \& Svetozarovova, N. (2016). Sustainable emarketing of selected tourism subjects from the Mediterranean through active online reputation management. In Smart City 360, 692-703. Springer, Cham.

5. Pollak, F., Dorcak, P., \& Markovic, P. (2019). Reputation Management. In Promotion and Marketing Communications. IntechOpen.

6. Ramos, C. M., \& Casado-Molina, A. M. Online corporate reputation: A panel data approach and a reputation index proposal applied to the banking sector. Journal of Business Research, 122, 121-130..

7. Benziman, Y. (2020). Reputation and morality. Human Affairs, 30(1), 109-119.

8. Servatka, M., Vadovic, R. (2009). Dovera - Kluc k produktivite a rozvoju. Retrieved from : http://www.virtualsciencelab.org/content_images/media/Dovera_ved.pdf

9. Soviar, J., Holubčík, M., Vodák, J., Rechtorík, M., \& Pollák, F. (2019). The Presentation of Automotive Brands in the On-Line Environment-The Perspective of KIA, Peugeot, Toyota and VW in the Slovak Republic. Sustainability, 11(7), 2132.

10. Helm, S., Liehr-Gobbers, K., \& Storck, C. (Eds.). (2011). Reputation management. Springer Science \& Business Media..

11. Lee, J., Kim, S. J., \& Kwon, I. (2017). Corporate social responsibility as a strategic means to attract foreign investment: Evidence from Korea. Sustainability, 9(11), 2121.

12. Svetozarovova, N., Pollák, F., Kaščáková, Z., Straková, J., \& Pártlová, P. (2020). Trust and faith as innovative marketing tools for providers in health care. European Journal of Science and Theology, 16(5), 69-76.

13. Shore, D. A. (2005). The trust prescription for healthcare: Building your reputation with consumers. Health Administration Press.

14. Anguera-Torrell, O. (2020). Entrepreneurship, trust and corruption. European Journal of Political Economy, 65, 101937.

15. Tavakolifard, M. (2012). On some challenges for online trust and reputation systems. 
16. Dorley, J., Garcia, F. H. (2015). Reputation Management: The Key to Successful Public Relations and Corporate Communication. New York : Routledge.

17. Zaki Ahmed, A., \& Rodríguez-Díaz, M. (2020). Analyzing the Online Reputation and Positioning of Airlines. Sustainability, 12(3), 1184 ..

18. Jones, B., Temperley, J., \& Lima, A. (2009). Corporate reputation in the era of Web 2.0: the case of Primark. Journal of marketing management, 25(9-10), 927-939.

19. Weber, L. (2007). Marketing to the social web: how digital customer communities build your business. Hoboken : John Wiley \& Sons.

20. Sasko, J. (2013). Analyza sentimentu vysledkov slovenskych firiem. Retrieved from: http://www.repu tation.sk/wp-content/uploads/2014/02/ORMreport.pdf

21. Dorcak, P., Markovic, P., Pollak, F. (2017). Multifactor analysis of online reputation as a tool for enhancing competitiveness of subjects from automotive industry. Journal of Economics, 65(2), 173-186.

22. DanielSoper free Sentiment Analyzer. (2019). Retrieved from: https://www.danielsoper.com/ sentimentanalysis/default.aspx

23. Socialbakers. (2019, December). 2019 Social Media Marketing Statistics. Retrieved from: http://socialbakers.com

24. Dorcak, P., Markovic, P., \& Pollak, F. (2017). Multifactor analysis of online reputation of selected car brands. Procedia engineering, 192, 719-724.

25. Pollak, F., Svetozarovova, N., \& Malinak, B. (2018). Multifactor analysis of online reputation as a tool for enhancing competitiveness of selected tourism entities. Global Business and Economics Review, 20(2), 231-247. 